\title{
KESESUAIAN PERAIRAN DAN DAYA DUKUNG LINGKUNGAN TANJUNG GELAM UNTUK WISATA REKREASI PANTAI DI TAMAN NASIONAL KARIMUNJAWA
}

\author{
Suitability Of Waters And Environmental Carrying Capacity For Recreational Tour Of Coastal Tanjung Gelam In \\ Karimunjawa National Park
}

\section{Kartika Puspita Dewi, Sutrisno Anggoro*, Siti Rudiyanti}

\author{
Program Studi Manajemen Sumberdaya Perairan, Departemen Sumberdaya Akuatik Fakultas Perikanan dan Ilmu \\ Kelautan, Universitas Diponegoro \\ J1. Prof Soedarto, SH, Tembalang, Semarang, Jawa Tengah - 50275, Telp/Fax. +6224 7474698 \\ Email : dewikartikapuspita@gmail.com
}

\begin{abstract}
ABSTRAK
Pantai Tanjung Gelam adalah salah satu objek wisata yang berada dibagian barat pulau Karimunjawa. Pantai ini termasuk kedalam kawasan Taman Nasional Karimunjawa, dan merupakan salah satu zona yang termasuk kedalam zona pemanfataan pariwisata. Penelitian ini bertujuan untuk mengkaji potensi wisata Pantai Tanjung Gelam, menganalisis indeks kesesuaian wisata pantai dan menganalisis daya dukung lingkungan Pantai Tanjung Gelam Pulau Karimunjawa, ditinjau dari aspek biogeofisik dan tata ruang. Penelitian dilakukan pada bulan April 2018. Metode yang digunakan dalam penelitian yaitu metode studi kasus dengan kajian adalah potensi wisata pantai, indeks kesesuaian wisata, daya dukung lingkungan dan teknik purposive sampling digunakan untuk menentukan tiga titik sampling berdasarkan lokasi kegiatan wisata dengan pertimbangan kemudahan dalam menjangkau lokasi titik sampling serta efisiensi waktu dalam melakukan penelitian. Penentuan persepsi daya tarik Pantai Tanjung Gelam menggunakan metode accidental sampling dengan membagikan 33 kuisioner kepada responden pengunjung. Potensi yang dimiliki Pantai Tanjung Gelam yaitu ekosistem terumbu karang dan karakteristik budaya lokal. Indeks kesesuaian wisata pantai Tanjung Gelam dari ke tiga stasiun memiliki kriteria S1 yaitu sangat sesuai untuk kegiatan wisata. Daya dukung kawasan di perairan pantai Tanjung Gelam dihitung berdasarkan indeks kesesuaian wisata kawasan dengan daya tampung 81 orang untuk bananaboat, daya tampung 135 orang untuk berenang dan daya tampung 17 orang untuk snorkling. Berdasarkan hasil penelitian disimpulkan bahwa Pantai Tanjung Gelam merupakan pantai yang sesuai untuk kegiatan wisata seperti rekreasi pantai, bananaboat dan snorkling dengan daya tampung sebanyak 233 orang/hari dalam kawasan tersebut.
\end{abstract}

Kata kunci : Indeks Kesesuaian Wisata, Daya Dukung, Pantai Tanjung Gelam

\section{ABSTRACT}

Tanjung Gelam Beach is one of the tourist attraction located in the western part of Karimunjawa island. This beach is included into the area of Karimunjawa National Park, and is one of the zones belonging to the zone of tourism utilization. The study aims to assess the potential for coastal tourism Tanjung Gelam Beach, analyze the suitability index of coastal tourism and analyze the environmental carrying capacity of Tanjung Gelam beach, Karimunjawa Island, in terms of biogeophysical and spatial aspects. This research was conducted in April 2018. The methods used in the research method of case studies with the study is the potential for coastal tourism, tourism, power suitability index support environment and purposive sampling technique was used to determine the three sampling points based on location tourism activities with consideration of ease in reaching out to the location of the sampling point and time efficiency in doing research. Determination of the perception of attractiveness of Tanjung Gelam method using accidental sampling with a respondent distributed a questionnaire to 33 respondents. The potential of Tanjung Gelam Beach is the coral reef ecosystem and the characteristics of local culture. Tanjung Gelam beach tourism suitability index of the three stations have S1 criteria that is suitable for tourism activities. The carrying capacity of the area in Tanjung Gelam coastal waters is calculated based on regional tourism suitability index with a capacity of 81 people for bananaboat, 135 people for swimming and 17 people for snorkeling capacity. Based on the research result, it is concluded that Tanjung Gelam Beach is a suitable beach for tourism activities such as beach recreation, bananaboat and snorkling with a capacity of 233 people / day in the area.

Keywords : Tourism Suitability Index, Carrying Capacity, Tanjung Gelam Beach

*) Penulis Penanggungjawab 


\section{PENDAHULUAN}

Kepulauan Karimunjawa sangat potensial sebagai tujuan wisata karena merupakan daerah kepulauan dengan topografi yang menyajikan keindahan alam asli, selain itu juga mempunyai keanekaragaman hayati seperti terumbu karang, lamun dan mangrove. Secara nasional kawasan Taman Nasional Karimunjawa bahkan telah ditetapkan sebagai daerah tujuan wisata.

Pantai Tanjung Gelam merupakan salah satu destinasi wisata yang favorit setelah melakukan perjalanan tour laut. Pantai ini terletak di desa Alang - alang Karimunjawa. Pantai Tanjung Gelam memiliki daya tarik tersendiri yaitu mempunyai hamparan pasir putih dan mempunyai batu - batuan granit yang besar serta memiliki banyak pepohonan yang lebat. Sebagaian besar kunjungan yang datang yaitu masyarakat lokal maupun masyarakat dari luar, wisatawan biasanya berkunjung di waktu hari libur maupun di waktu sore bersama keluarga ataupun sendiri untuk menyaksikan terbenamnya matahari.

Ekowisata pada saat sekarang ini menjadi aktivitas ekonomi yang penting yang memberikan kesempatan kepada wisatawan untuk mendapatkan pengalaman mengenai alam dan budaya untuk dipelajari dan memahami betapa pentingnya konservasi keanekaragaman hayati dan budaya lokal. Berdasarkan kemajuan ilmu pengetahuan dan teknologi memudahkan wisatawan untuk menentukan destinasti wisatanya.

Pengendalian aktivitas dan jumlah wisatawan yang berada pada kawasan Pantai Tanjung Gelam merupakan satu diantara konsep pelestarian lingkungan yang lestari, dengan menganalisis kesesuaian dan tingkat daya dukung pada kawasan wisata Pantai Tanjung Gelam.

Tujuan Penelitian ini adalah Mengetahui Potensi Wisata Pantai Tanjung Gelam di Pulau Karimunjawa, Menghitung / menentukan Indeks Kesesuaian Wisata Pantai, Menganalisis Daya Dukung Lingkungan Pantai Tanjung Gelam Pulau Karimunjawa, ditinjau dari aspek biogeofisik dan tata ruang.

\section{METODE PENELITIAN}

a. Waktu dan Lokasi penelitian

Kegiatan penelitian ini dilaksakan pada bulan April 2018 di Pantai Tanjung Gelam, Pulau Karimunjawa.

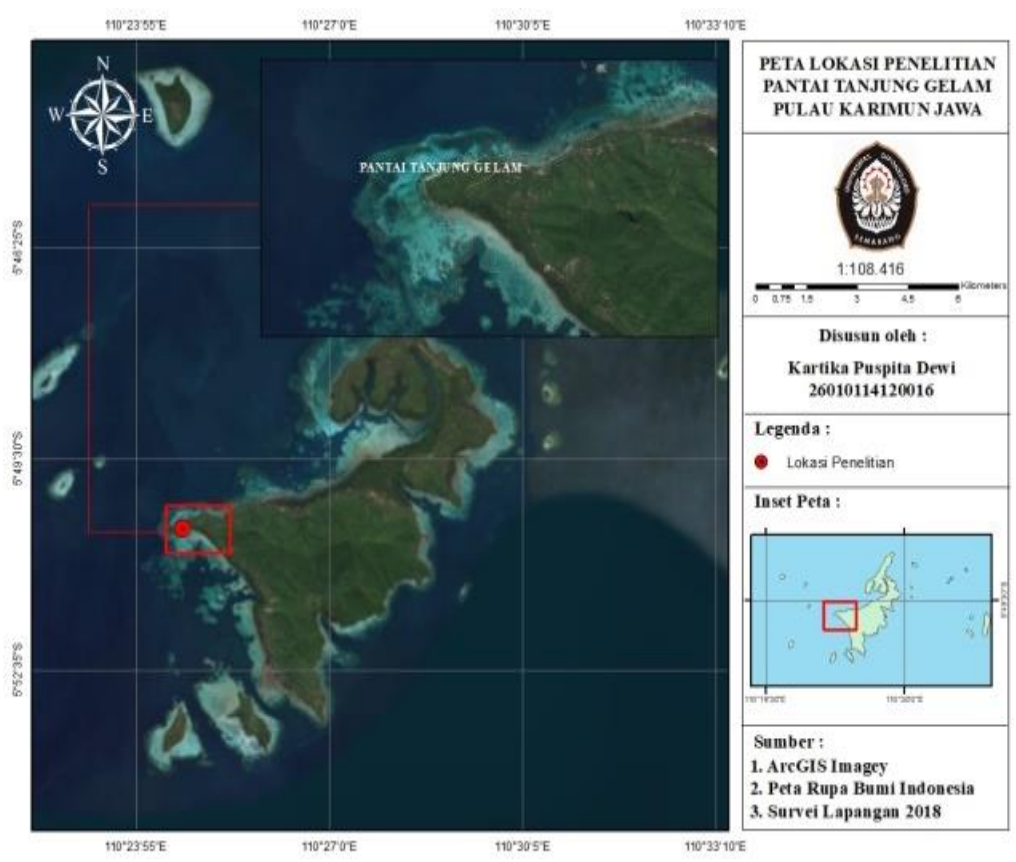

Gambar 1. Peta Lokasi Penelitian

Metode yang digunakan pada penelitian ini adalah metode Studi kasus. Kasus yang diteliti adalah indeks potensi kesesuaian wisata, dan daya dukung lingkungan. Pengumpulan data primer dengan pengamatan dan pengukuran secara langsung di lapangan terhadap kondisi sumberdaya pesisir dan laut. Penetapan responden pengunjung dengan cara accidental sampling. Sedangkan dalam menentukan titik sampling parameter biogeofisik menggunakan teknik purposive sampling, berdasarkan pertimbangan kemudahan dalam menjangkau lokasi titik sampling serta efisiensi waktu dalam melakukan penelitian. Pengambilan sampel hanya terbatas pada unit sampel yang sesuai dengan kriteria kriteria tertentu yang tetap berdasarkan tujuan peneliti. Susunan petunjuk Sugiyono (2012) tentang teknik penentuan sampel dengan pertimbangan tertentu.

Lokasi pengambilan sampel sebanyak 3 titik sampling diharapkan sudah dapat mewakili semua kondisi perairan lokasi penelitian. Setiap lokasi pengamatan titik sampling selalu dicatat posisi geografisnya dengan alat penentu posisi yaitu GPS. Data yang di hasilkan yaitu dari data Primer dan Sekunder yang bersumber dari instansi terkait dan berbagai pustaka dan peneliti yang relevan. 
Penentuan responden dilakukan dengan metode accidental sampling, artinya responden yang diperoleh secara kebetulan sedang berada dan dijumpai di Pantai Tanjung Gelam. Menurut Sugiyono, (2012) accidental sampling merupakan penentuan sampel berdasarkan faktor kebetulan, yakni siapa saja yang secara kebetulan dijumpai di lokasi tersebut dan bersedia diwawancarai. Membagikan 33 kuisioner kepada pengunjung, perhitungan penentuan sampel pengunjung menggunakan metode slovin dengan derajat kecermatan $10 \%$, berikut ini rumus penentuan sampel kuisioner adalah:

$\mathrm{n}=\frac{N}{n e^{2}+1}$

Keterangan: n: Jumlah responden N: Ukuran populasi e: Presentase kelonggaran ketelitian kesalahan pengambilan sampel yang masih bisa ditolerir.

\section{b. Alat dan Bahan}

Alat yang digunakan pada saat penelitian dapat dilihat pada Tabel 1.

Alat yang digunakan dalam penelitian ini terdiri atas Global Positioning System yang digunakan untuk menemukan koordinat titik pengambilan data, rollmeter yang digunakan untuk mengukuran panjang, lebar dan alat bantu untuk mengukur kemiringan pantai, secchi disk yang digunakan untuk mengukur kecerahan perairan, tongkat berskala yang digunakan untuk mengukur kedalaman perairan, tongkat berukuran $200 \mathrm{~cm}$ yang digunakan untuk mengukur kemiringan pantai, current meter yang digunakan untuk mengukuran kecepatan arus, stopwatch digunakan untuk menentukan lamanya waktu pengamatan, kamera digunakan sebagai alat dokumentasi kegiatan penelitian, alat tulis digunakan untuk mencatat hasil penelitian dan kuisioner digunakan sebagai daftar pertanyaan.

\section{c. Metode pengumpulan data \\ Data Parameter Rekreasi Pantai \\ Kedalaman}

Pengukuran parameter dilakukan pada siang hari, dan lokasi pengambilan data yaitu berjarak kurang lebih 15 meter ke arah laut dari garis pantai yang dianggap aman untuk kegiatan wisata pantai. Pengambilan data ini dilakukan dengan tongkat berskala yang dimasukkan kedalam badan perairan. Hal ini diperkuat oleh Febyanto et al., (2014) Kedalaman perairan dalam penelitian ini diukur pada siang hari dan saat air laut sedang pasang, di lokasi yang berjarak $15 \mathrm{~m}$ dari garis pantai, yang dianggap aman untuk kegiatan berenang atau kegiatan bermain air.

\section{Kecerahan}

Pengukuran kecerahan dilakukan dengan menggunakan secchi disk yang diikat dengan tali kemudian diturunkan perlahan - lahan ke dalam perairan pada lokasi pengamatan. Kecerahan perairan adalah rata - rata dari kedalaman secchi disk tidak terlihat dan kedalaman secchi disk yang sudah terlihat kembali. Menurut Effendi (2003) nilai kecerahan dapat dipengaruhi oleh padatan tersuspensi dan kekeruhan, keadaan cuaca, waktu pengukuran, serta ketelitian orang yang melakukan pengukuran.

\section{Tipe Pantai}

Penentuan tipe pantai dilakukan secara pengamatan visual, yaitu dengan mengamati jenis dan warna pasir yang ada di stasiun tersebut. Pantai yang berpasir putih, sesuai untuk kegiatan wisata. Hal ini diperkuat oleh Sitompul et al., (2013) pantai berupa pantai berpasir putih warna pasir yang putih bersih, akan memberikan nilai tambah bagi keindahan dan kenyamanan wisatawan.

\section{Lebar Pantai}

Menurut Chasanah et al., (2017) Pengukuran lebar pantai dilakukan menggunakan rollmeter, yang diukur jarak antara vegetasi terakhir yang ada di pantai dengan batas pasang surut terendah pada saat pengambilan sampel.

\section{Material Dasar Perairan}

Penentuan material dasar perairan dengan mengamati bentuk dari substrat, dan kemudian digolongkan apakah termasuk substrat pasir, berkarang, pasir berlumpur atau substrat lumpur. Menurut Hazen et al., (2016) Material/substrat dasar sangat menentukan keecerahan perairan. Material dasar perairan diukur dengan cara mengamati dasar perairan secara langsung.

\section{Kecepatan Arus}

Pengukuran arus berjarak 15 meter kearah laut dari garis pantai yang dianggap aman untuk kegiatan wisata pantai. Kecepatan arus di ukur menggunakan bola arus, yaitu dengan menetapkan jarak tempuh bola arus dan kemudian diukur waktu tempuh bola arus tersebut. Menurut Sudarto et al., (2013) kecepatan arus dapat diukur dengan rumus:

$$
\mathrm{v}=\mathrm{s} / \mathrm{t}
$$


Dengan $v=$ kecepatan arus $(\mathrm{m} / \mathrm{s}) s=$ jarak yang ditempuh (m) dan $t=$ waktu yang ditempuh (detik).

\section{Kemiringan Pantai}

Pengukuran kemiringan pantai dilakukan dengan menggunakan tongkat berukuran $200 \mathrm{~cm}$ diletakan secara horizontal di atas pasir dan diatasnya diletakan waterpass, dilakukan tepat pada batas pantai teratas. Hitung ketinggian tongkat dengan bantuan rollmeter dan akan didapatkan sudut kemiringan pantai. Menurut Masrukhin et al., (2014) Pengukuran kemiringan pantai dilakukan dengan menggunakan tongkat kayu atau waterpass yang dimulai dari batas vegetasi terluar kemudian dilanjutkan sampai ke batas pantai yang tepat menyentuh air dihitung dengan menggunakan rumus Panjaitan et al., (2012) bahwa:

Keterangan :

$$
\alpha=\arctan \frac{\mathrm{Y}}{\mathrm{X}}
$$

$\alpha=$ sudut yang dibentuk $\left(^{\circ}\right) \mathrm{Y}=$ Jarak antara garis tegak lurus yang dibentuk oleh kayu horizontal dengan permukaan pasir dibawahnya $\mathrm{X}=$ panjang kayu $(200 \mathrm{~cm})$

\section{Pengamatan Biota Berbahaya}

Pengamatan biota berbahaya perlu dilakukan untuk megetahui ada atau tidaknya biota berbahaya yang akan menggangu pengunjung wisata. Pengamatan biota berbahaya dilakukan berdasarkan snorkeling di sekitar stasiun penelitian. Menurut Kamah et al., (2013), biota yang berbahaya bagi pengunjung wisata diantaranya gastropoda, karang api, bulu babi, ubur-ubur, anemon dan ular laut.

\section{Ketersediaan Air Tawar}

Ketersediaan air merupakan hal penting dalam suatu kehidupan. Tidak hanya untuk sektor rumah tangga, melainkan juga untuk menunjang wisatawan dalam melakukan kegiatan wisata. Pengamatan ketersediaan air tawar dilakukan dengan cara mengukur jarak antara stasiun penelitian dengan lokasi dimana sumber air tawar tersedia (Kamah et al., 2013).

\section{d. Analisis Data}

\section{Analisis Kesesuaian}

Analisis kesesuaian kawasan untuk rekreasi pantai memiliki dua kategori yaitu: Kesesuaian Kawasan untuk wisata pantai rekreasi diantaranya, kedalaman, tipe Pantai, lebar pantai, material dasar perairan, kecepatan arus (m/dt), kecerahan $(\mathrm{m})$, kemiringan pantai, biota berbahaya, ketersedian air tawar $(\mathrm{km})$.

Berdasarkan matriks indeks kesesuaian wisata yang tersaji pada tabel 2 yang dibawah ini:

Tabel 2. Indeks Kesesuaian Rekreasi Pantai

\begin{tabular}{|c|c|c|c|c|c|}
\hline Parameter & Bobot & $\begin{array}{l}\text { Kategori S1 } \\
(3)\end{array}$ & $\begin{array}{l}\text { Kategori S2 } \\
\text { (2) }\end{array}$ & $\begin{array}{l}\text { Kategori S3 } \\
\text { (1) }\end{array}$ & $\begin{array}{l}\text { Kategori } \\
\mathrm{N}(0)\end{array}$ \\
\hline $\begin{array}{l}\text { Kedalaman } \\
\text { perairan }\end{array}$ & 5 & $0-3$ & $>3-6$ & $>6-10$ & $>10$ \\
\hline Tipe pantai & 5 & Pasir putih & $\begin{array}{l}\text { Pasir putih } \\
\text { karang }\end{array}$ & $\begin{array}{l}\text { Pasir hitam, } \\
\text { karang terjal }\end{array}$ & $\begin{array}{l}\text { Lumpur berbatu } \\
\text { terjal }\end{array}$ \\
\hline Lebar pantai (m) & 5 & $>15$ & $10-15$ & $3-<10$ & $<3$ \\
\hline $\begin{array}{l}\text { Material dasar } \\
\text { perairan }\end{array}$ & 3 & Pasir & $\begin{array}{l}\text { Karang } \\
\text { berpasir }\end{array}$ & Pasir lumpur & Lumpur \\
\hline $\begin{array}{l}\text { Kecepatan arus } \\
(\mathrm{m} / \mathrm{dtk})\end{array}$ & 3 & $0-0,17$ & $>0,17-0,34^{*}$ & $>0,34-0,51^{*}$ & $>0,51$ \\
\hline $\begin{array}{l}\text { Kemiringan Pantai } \\
\left(^{\circ}\right)\end{array}$ & 3 & $<10$ & $10-25$ & $>25-45$ &.$>45$ \\
\hline Kecerahan perairan & 1 & $>10$ & $>5-10$ & $3-5$ & $<2$ \\
\hline $\begin{array}{l}\text { Penutupan Lahan } \\
\text { pantai }\end{array}$ & 1 & $\begin{array}{l}\text { Kelapa, } \\
\text { Lahan } \\
\text { terbuka }\end{array}$ & $\begin{array}{l}\text { Semak } \\
\text { Belukar, } \\
\text { rendah, } \\
\text { savana }\end{array}$ & $\begin{array}{l}\text { Belukar } \\
\text { tinggi, }\end{array}$ & $\begin{array}{l}\text { Hutan bakau, } \\
\text { pemukiman, } \\
\text { pelabuhan }\end{array}$ \\
\hline Biota Berbahaya & 1 & Tidak ada & Bulu babi & $\begin{array}{l}\text { Bulu babi, } \\
\text { ikan pari }\end{array}$ & $\begin{array}{l}\text { Bulu babi, ikan } \\
\text { pari, lepu, hiu }\end{array}$ \\
\hline $\begin{array}{l}\text { Ketersediaan air } \\
\text { tawar }\end{array}$ & 1 & $<0,5(\mathrm{~km})$ & $>0,5-1(\mathrm{~km})$ & $>1-2$ & $>2(\mathrm{~km})$ \\
\hline
\end{tabular}

Sumber: Modifikasi Yulianda, (2007)*

Keterangan : Nmaks: 84 S1: Sangat Sesuai, dengan IKW 75-100 \% S2: Cukup Sesuai 50 - <75\% S3: Sesuai Bersyarat $<50 \%$ N: Tidak Sesuai 


\section{Analisis Daya Dukung}

Daya dukung (carrying capacity) merupakan kemampuan kawasan dalam menerima wisatawan dengan intensitas jumlah penggunaan terhadap sumberdaya alam yang berlangsung secara terus - menerus tanpa merusak lingkungan. daya dukung perlu diketahui secara fisik, lingkungan dan sosial yang mana dalam studi ini mengkaji tentang jumlah wisatawan yang berkunjung, pelayanan, jenis wisata yang dikembangkan beserta sarananya. Adapun rumus yang digunakan dalam mengitung yaitu : Menurut Yulianda et al., (2010)

Keterangan :

$$
\mathrm{DDK}=\mathrm{K} \times \mathrm{Lp} / \mathrm{Lt} \times \mathrm{Wt} / \mathrm{Wp}
$$

DDK = Daya Dukung Kawasan $\mathrm{K}=$ Potensi ekologis pengunjung per satuan unit area $\mathrm{Lp}=$ Luas area atau panjang area yang dimanfaatkan $\mathrm{Lt}=$ Unit area untuk kategori tertentu $\mathrm{Wt}=$ Waktu yang disediakan kawasan untuk kegiatan wisata dalam 1 hari $\mathrm{Wp}=$ Waktu yang dihabiskan oleh pengunjung untuk setiap kegiatan tertentu.

Berdasarkan matriks daya dukung kawasan yang tersaji pada tabel 3 dibawah ini:

Tabel 3. Matriks Daya Dukung

\begin{tabular}{|c|c|c|c|c|c|}
\hline Jenis kegiatan & $\begin{array}{l}\sum \text { Pengunjung (K) } \\
\text { (orang) }\end{array}$ & $\begin{array}{l}\text { Unit area } \\
(\mathrm{Lt})\end{array}$ & $\begin{array}{l}\text { Waktu } \\
\text { Pengunjung } \\
\text { (Wt) }\end{array}$ & $\begin{array}{l}\text { Waktu } \\
\text { Wisata } \\
\text { (Wp) }\end{array}$ & Keterangan \\
\hline Snorkling & 1 & $500 \mathrm{~m}^{2}$ & 1 & 9 & $\begin{array}{l}\text { Setiap } 1 \text { orang dalam } \\
100 \times 5 \mathrm{~m}\end{array}$ \\
\hline Bananboat & 1 & $500 \mathrm{~m}^{2}$ & 1 & 9 & $\begin{array}{l}\text { Setiap } 1 \text { orang dalam } \\
100 \times 5 \mathrm{~m}\end{array}$ \\
\hline $\begin{array}{l}\text { Rekreasi Pantai/ } \\
\text { Berenang }\end{array}$ & 1 & $50 \mathrm{~m}$ & 2 & 13 & $\begin{array}{l}1 \text { orang setiap } 50 \mathrm{~m} \\
\text { panjang pantai }\end{array}$ \\
\hline
\end{tabular}

Modifikasi Yulianda et al., (2010)

\section{HASIL DAN PEMBAHASAN}

\section{Gambaran Umum Lokasi Penelitian}

Taman Nasional Karimunjawa terletak di sebelah timur laut kota Semarang dan Taman Nasional Karimunjawa adalah kepulauan Laut Jawa yang termasuk kedalam Kabupaten Jepara Jawa Tengah dengan luas kawasan 111.625 Hektar. Taman Nasional Karimunjawa secara geografis terletak pada koordinat $5^{\circ} 40^{\prime} 39^{\prime \prime}-5^{\circ} 55^{\prime} 00^{\prime \prime} L S$ dan $110^{\circ} 05^{\prime} 57^{\prime \prime}-110^{\circ} 31^{\prime} 15^{\prime \prime}$ BT. Kepulauan Karimunjawa termasuk dalam wilayah administrasi Kecamatan Karimunjawa, Kabupaten Jepara yang terdiri dari tiga Desa yaitu Desa Karimunjawa, Kemujan dan Parang. Pantai Tanjung Gelam merupakan daratan yang menjorok ke arah lautan, yang letaknya masih di dalam kawasan Karimunjawa. Pantai ini sering dikunjungi oleh wisatawan yang berlibur ke Karimunjawa ketika sedang mengikuti acara tour laut. Letak Pantai Tanjung Gelam bersebelahan dengan pantai Batu Topeng dimana pantai ini sama - sama memiliki pemandangan hamparan pasir putih yang sangat indah.

\section{Potensi Pantai Tanjung Gelam}

Potensi yang ada di Pantai Tanjung gelam yaitu berupa potensi alam dan budaya. Potensi alam yang dimiliki Pantai Tanjung Gelam berupa pemandangan hamparan pasir putih dan pohon kelapa yang tumbuh berjejer dipinggir pantai, hal ini menjadikan salah satu daya tarik tersendiri bagi wisatawan serta keindahan bawah laut terumbu karang yang terdapat berbagai bermacam ikan hias. Potensi budaya yang ada di Pantai Tanjung Gelam adalah tradisi sedekah laut yang merupakan sebuah bentuk rasa syukur kepada sang pencipta. Tradisi sedekah laut bertujuan sebagai bentuk wujud syukur kepada Tuhan atas limpahan kekayaan laut yang dapat menghidupi para nelayan. Tradisi sedekah laut juga disebut dengan nama Pesta Lomban dan dilaksanakan pada hari ketujuh setelah Idul Fitri.

\section{Analisis Kesesuaian Wisata}

Indeks kesesuaian wisata adalah kecocokan suatu lahan untuk tujuan atau penggunaan tertentu, melalui penentuan nilai (kelas) atau tata guna lahan yang dihubungkan dengan potensi wilayahnya. Sehingga dapat diusahakan penggunaan lahan yang lebih terarah dengan usaha pemeliharaan kelestariannya Kumaat et al., (2017). Kesesuaian wisata digunakan untuk mengetahui kesesuaian lahan wisata yang digunakan untuk kegiatan wisata. Pengukuran parameter kesesuaian wisata pantai meliputi kedalaman perairan, kecepatan arus, kemiringan pantai, kecerahan perairan, penutupan lahan pantai, biota berbahaya dan ketersediaan air tawar.

Berdasarkan hasil penelitian analisis kesesuaian wisata yang tersaji pada Tabel 4: 
Tabel 4. Hasil Analisis Kesesuaian Wisata Rekreasi Pantai

\begin{tabular}{|c|c|c|c|c|c|c|c|c|c|c|}
\hline \multirow{2}{*}{$\begin{array}{l}\text { Paramete } \\
\mathbf{r}\end{array}$} & \multirow{2}{*}{ Bobot } & \multicolumn{9}{|c|}{ Keterangan } \\
\hline & & Stasiun 1 & Skor & Jumlah & Stasiun 2 & Skor & Jumlah & Stasiun 3 & Skor & Jumlah \\
\hline $\begin{array}{l}\text { Kedalama } \\
\mathrm{n} \text { perairan } \\
\text { (m) }\end{array}$ & 5 & 0,92 & 3 & 15 & 1,05 & 3 & 15 & 0,81 & 3 & 15 \\
\hline $\begin{array}{l}\text { Tipe } \\
\text { Pantai }\end{array}$ & 5 & $\begin{array}{c}\text { Pasir Putih } \\
\text { Sedikit } \\
\text { Karang }\end{array}$ & 2 & 10 & $\begin{array}{c}\text { Pasir Putih } \\
\text { Sedikit } \\
\text { Karang }\end{array}$ & 2 & 10 & $\begin{array}{l}\text { Pasir } \\
\text { Putih }\end{array}$ & 3 & 15 \\
\hline $\begin{array}{l}\text { Lebar } \\
\text { Pantai } \\
\text { (m) }\end{array}$ & 5 & 20 & 3 & 15 & 24 & 3 & 15 & 15 & 3 & 15 \\
\hline $\begin{array}{l}\text { Material } \\
\text { dasar } \\
\text { perairan }\end{array}$ & 5 & Pasir & 3 & 15 & Pasir & 3 & 15 & Pasir & 3 & 15 \\
\hline $\begin{array}{l}\text { Kecepata } \\
\mathrm{n} \text { arus } \\
(\mathrm{m} / \mathrm{s})\end{array}$ & 3 & 0,03 & 3 & 9 & 0,1 & 3 & 9 & 0,1 & 3 & 9 \\
\hline $\begin{array}{l}\text { Kemiring } \\
\text { an pantai } \\
\left(^{\circ}\right)\end{array}$ & 3 & 7,4 & 3 & 9 & 9,6 & 3 & 9 & 3,4 & 3 & 9 \\
\hline $\begin{array}{l}\text { Keceraha } \\
\text { n perairan } \\
(\%)\end{array}$ & 1 & 100 & 0 & 0 & 100 & 0 & 0 & 100 & 0 & 0 \\
\hline $\begin{array}{l}\text { Penutupa } \\
\text { n lahan }\end{array}$ & 1 & $\begin{array}{c}\text { Kelapa, } \\
\text { lahan } \\
\text { terbuka }\end{array}$ & 3 & 3 & $\begin{array}{l}\text { Semak } \\
\text { belukar, } \\
\text { rendah, } \\
\text { savana }\end{array}$ & 2 & 2 & $\begin{array}{c}\text { Belukar } \\
\text { tinggi }\end{array}$ & 1 & 1 \\
\hline $\begin{array}{l}\text { Biota } \\
\text { berbahaya }\end{array}$ & 1 & Tidak ada & 3 & 3 & Tidak ada & 3 & 3 & Tidak ada & 3 & 3 \\
\hline $\begin{array}{l}\text { Ketersedi } \\
\text { aan air } \\
\text { tawar } \\
(\mathrm{km})\end{array}$ & 1 & 0,39 & 3 & 3 & 0,58 & 2 & 2 & 0,71 & 2 & 2 \\
\hline Total $\sum(\mathrm{Ni})$ & & & & 82 & & & 80 & & & 84 \\
\hline IKW $(\%)$ & & & & 98 & & & 95 & & & 100 \\
\hline Kriteria & & & & S1 & & & S1 & & & S1 \\
\hline
\end{tabular}

Sumber : Analisis data 2018

Nilai Indeks kesesuaian rekreasi Pantai Tanjung Gelam pada tabel 4. menunjukan tingkat kelayakan ekowisata Pantai Tanjung Gelam sebagai kesesuaian kawasan ekowisata pantai. Berdasarkan hasil penelitian analisis kesesuaian lokasi wisata pada ketiga stasiun didapatkan kategori S1 dengan nilai 75\%-100\% ( sangat sesuai). Parameter yang diukur dari kesesuaian wisata adalah sebagai beriku:

\section{Kedalaman}

Hasil dari Pengukuran kedalaman pada ke tiga stasiun yaitu stasiun I yaitu 0,92 meter, stasiun II yaitu 1,05 meter dan pada stasiun III yaitu 0,81 meter. Kedalaman perairan adalah jarak dari permukaan perairan hingga ke dasar perairan, Perairan Tanjung Gelam tidak tergolong dalam perairan dalam hal ini dilihat dari hasil pengukuran pada ketiga stasiun yaitu 0-1 m. Adanya variasi dari tingkat kedalaman yaitu tergantung dari kondisi topografi pantai, menurut Nugraha et al., (2013) kedalaman yang baik untuk kegiatan wisata rekreasi pantai yaitu 0-5 meter. Hal ini berarti hasil dari pengukuran kedalaman perairan Tanjung Gelam baik untuk kegiatan wisata rekreasi pantai dan berenang. Suatu kedalaman perairan sangatlah penting untuk melakukan kegiatan wisata, hal ini dikarenakan untuk menjaga keselamatan dan keamanan pengunjung dalam berwisata. Hal ini diperkuat oleh Yulisa et al., (2016) bahwa kedalaman merupakan aspek yang cukup penting dalam penentu suatu kawasan untuk kegiatan wisata karena sangat berpengaruh terhadap keselamatan pada saat berenang maupun rekreasi. 


\section{Kemiringan}

Pengukuran kemiringan pantai Tanjung Gelam mendapatkan hasil pada stasiun 1 yaitu sebesar 7,4 $4^{\circ}$, stasiun II yaitu sebesar $9,6^{\circ}$ dan stasiun III yaitu sebesar $3,4^{\circ}$. Hal ini berarti pantai tanjung gelam memiliki kemiringan pantai yang landai, yaitu $<10^{\circ}$. Hal ini diperkuat oleh Nugraha et al., (2013) bahwa kemiringan pantai yang landai merupakan karakteristik dari pantai berpasir putih yang memiliki nilai kemiringan pantai $<10^{\circ}$. Kemiringan pantai yang landai sangat sesuai untuk kegiatan wisata pantai khususnya berenang. Menurut Hendyanto et al., (2014) bahwa kemiringan pantai merupakan faktor keamanan yang dapat mempengaruhi wisatawan pada kegiatan wisata tersebut.

\section{Kecerahan}

Hasil Pengukuran kecerahan pada perairan Tanjung Gelam di tiga stasiun yaitu stasiun I, stasiun II dan stasiun III memiliki hasil yang sama yaitu seratus persen atau kecerahan sama dengan kedalaman hal ini dikarenakan perairan tanjung gelam merupakan perairan yang dangkal sehingga cahaya matahari dapat menembus perairan, kecerahan perairan tertinggi terjadi pada siang hari hingga menjelang sore hari yang disebabkan banyaknya kapasitas cahaya yang dapat diserap oleh perairan. Pengukuran kecerahan dilakukan dengan menggunakan secchi disk yang diturunkan perlahan ke badan perairan. Hal ini diperkuat oleh Yulisa et al., (2016) bahwa pengukuran kecerahan dilakukan dengan menggunakan secchi disk yang diikat dengan tali dan kemudian diturunkan perlahan kedalam perairan sampai batas visual secchi disk itu tidak terlihat.

\section{Kecepatan Arus}

Hasil pengukuran kecepatan arus di kawasan wisata pantai tanjung gelam termasuk dalam golongan kecepatan arus yang kecil, hal ini diperoleh dari hasil kecepatan arus pada stasiun I adalah $0,03 \mathrm{~m} / \mathrm{s}$, stasiun II $0,1 \mathrm{~m} / \mathrm{s}$ dan stasiun III $0,1 \mathrm{~m} / \mathrm{s}$. Kecepatan arus yang rendah yaitu sangat baik untuk kegiatan wisata berenang dan rekreasi pantai, hal ini dikarenakan kecepatan arus berkaitan dengan kenyamanan dan kemananan pengunjung saat berrekreasi. Menurut Yulisa et al., (2016) bahwa kecepatan arus berkaitan dengan kenyamanan pengunjung yang datang ke objek wisata, jika arus kencang maka penggunjung diharapkan tidak melakukan aktivitas ekowisata karena berbahaya bagi pengunjung yang datang, jika kecepatan arus relative tenang maka akan memberikan kesan kenyamanan bagi pengunjung yang ingin melakukan kegiatan wisata.

\section{Tipe Pantai}

Berdasarkan hasil pengamatan dari tipe pantai tanjung gelam di stasiun I yaitu memiliki tipe pantai yang berpasir putih dan sedikit karang, stasiun II sama dengan stasiun I yaitu memiliki tipe pantai berpasir putih dan sedikit karang sedangkan pada stasiun III memiliki tipe pantai yaitu berpasir putih. Tipe pantai berpasir sangat sesuai untuk kegiatan wisata dari pada tipe pantai yang berlumpur. Hal ini diperkuat oleh Saputra dan Khodijah (2014) bahwa pantai berpasir merupakan lokasi yang ideal untuk kegiatan wisata pantai, seperti halnya para pengunjung leluasa berjemur, berolahraga, menikmati pemandangan dan bermain pasir pantai dengan aman dan nyaman.

\section{Lebar Pantai}

Hasil pengamatan dari parameter lebar pantai Tanjung Gelam adalah pada stasiun I yaitu $20 \mathrm{~m}$, stasiun II yaitu 24 $\mathrm{m}$ dan stasiun III yaitu $15 \mathrm{~m}$. Lebar pantai Tanjung gelam ini termasuk pantai yang sesuai digunakan untuk kegiatan wisata, karena pantai memiliki lebar lebih dari $15 \mathrm{~m}$. Lebar pantai sangat mempengaruhi aktivitas yang dilakukan pengunjung, semakin lebar pantai maka semakin baik pengunjung dalam melakukan aktivitasnya. Hal ini diperkuat oleh Hendyanto et al., (2014) bahwa pantai dengan dominasi lebar lebih dari 15 meter sangat sesuai untuk kegiatan wisata pantai seperti berjemur, dan susur pantai.

\section{Material Dasar Perairan}

Hasil pengamatan dari material dasar perairan pada pantai Tanjung Gelam di stasiun I,II dan III menunjukan bahwa ketiga stasiun memiliki dasar perairan dengan material berpasir. Material dasar berpasir putih sangat sesuai untuk kegiatan wisata rekreasi dan berenang, material dasar perairan merupakan salah satu penunjang bagi pengunjung dalam hal kegiatan wisata semakin sesuai material dasar perairan tersebut maka semakin banyak ketertarikan pengunjung untuk datang ke suatu objek wisata tersebut. Hal ini diperkuat oleh Juliana et al., (2013) bahwa material dasar perairan merupakan salah satu faktor yang mempengaruhi ekosistem perairan yang sangat berpengaruh terhadap kekeruhan perairan dan juga merupakan salah satu penunjang untuk kelayakan aktivitas wisata.

\section{Penutupan Lahan}

Pantai Tanjung Gelam memiliki berbagai area penutupan lahan yaitu pada stasiun I tipe penutupan lahan kelapa, lahan terbuka, Stasiun II tipe penutupan lahan semak belukar rendah savana dan stasiun III tipe penutupan lahan belukar tinggi. Kriteria penutupan lahan di pantai tanjung gelam memiliki kesesuaian untuk kawasan kegiatan wisata, karena pada kawasan tersebut ditumbuhi pepohonan yang menyebabkan pantai tanjung gelam ini memiliki keindahan tersendiri bagi wisatawan yang berkunjung. Menurut Tambunan et al., (2013) bahwa penutupan lahan dalam matriks kesesuaian wisata rekreasi dan berenang terbagai menjadi lahan terbuka dan kelapa, semak belukar rendah dan semak belukar 
tinggi, pemukiman dan pelabuhan, jenis tutupan lahan yang terbuka merupakan jenis tutupan lahan yang sesuai untuk aktivitas wisata.

\section{Biota Berbahaya}

Pengamatan pada biota berbahaya sangat perlu dilakukan karena untuk kepentingan dan kenyamanan pengunjung disaat melakukan kegiatan wisata. Pengamatan dari ketiga stasiun yang ada di pantai Tanjung Gelam ini tidak ditemukan biota berbahaya di setiap stasiunnya, sehingga kawasan ini aman untuk pengunjung yang akan melakukan kegiatan berenang. Hal ini diperkuat oleh Hendyanto et al., (2014) bahwa biota berbahaya merupakan faktor yang dipertimbangkakan pengunjung dalam hal melakukan kegiatan wisata.

\section{Ketersediaan Air Tawar}

Ketersediaan air tawar yang ada di pantai tanjung gelam ini memiliki jarak yang dekat dengan pinggir pantai. Ketersediaan air twar yang ada di pantai Tanjung Gelam pada stasiun I berjarak 0,39 atau 390 meter, stasiun II 0,58 atau 580 meter dan stasiun III berjarak 0,71 atau 170 meter. Perbedaan ini dikarenakan letak wc/kamar mandi berdekatan dengan stasiun I. Keberadaan air tawar yang cukup dapat memenuhi kebutuhan pengunjung, fasilitas yang disediakan berupa wc/kamar mandi telah tersedia air bersih sehingga dapat digunakan pengunjung untuk membersihkan diri setelah melakukan kegiatan wisata. Menurut Handayawati et al., (2010) kesesuaian wisata dengan jarak ketersediaan air tawar yang paling sesuai untuk kegiatan wisata pantai adalah $<500$ meter atau $0,5 \mathrm{~km}$ dalam ketersediaan air bersih sangat diperlukan untuk menunjang fasilitas pelayanan yang ada di pantai tersebut.

\section{Daya Dukung Kawasan dan Daya Tampung}

Berdasarkan hasil penelitian analisis daya dukung yang tersajikan pada tabel 5 dibawah ini:

\begin{tabular}{|c|c|c|}
\hline No & Kegiatan wisata & DDK(orang/hari) \\
\hline 1 & $\begin{array}{l}\text { Rekreasi Pantai/ } \\
\text { Berenang }\end{array}$ & 135 \\
\hline 2 & Snorkling & 17 \\
\hline 3 & Bananaboat & 81 \\
\hline
\end{tabular}

Sumber : Analisis Data 2018

Perhitungan daya dukung kawasan dilakukan dengan menghitung setiap lokasi wisata yang dianggap sesuai dan sangat sesuai sesuai dengan asumsi wisatawan. Perhitungan rekreasi pantai dilakukan berdasarkan panjang dan luas pantai, sedangkan untuk perhitungan wisata snorkling dan bananaboat yaitu berdasarkan luas kawasan yang sesuai dan sangat sesuai.

Daya dukung merupakan variabel penting yang perlu mendapat perhatian khusus dalam upaya pemanfaatan sumberdaya alam dan lingkungan sesuai ukuran kemampuannya agar tetap lestari dan berkelanjutan. Daya dukung juga merupakan faktor pembatas yang dapat membatasi berbagai aktifitas manusia dalam memanfaatkan sumberdaya sesuai dengan kemampuannya agar tidak terjadi kemerosotan. (Indarjo, 2012).

Berdasarkan total hasil analisis daya dukung kawasan pantai Tanjung Gelam yaitu Berenang, snorkling dan bananboat adalah 233 orang, dengan luasan area kawasan $7.920 \mathrm{~m}^{2}$. Jumlah kawasan yang datang memenuhi syarat daya dukung kawasan dengan total pengunjung dalam kegiatan seluruhnya. Analisi daya dukung kawasan menjadi pertimbangan dalam suatu kegiatan wisata, sehingga di masa mendatang kawasan wisata akan lebih berkembang dalam menampung wisatawan hingga tidak melebihi daya dukung kawasan yang ada. hal ini agar keberlanjutan kegiatan wisata di Pantai Tanjung Gelam tetap terjaga.

\section{KESIMPULAN}

Potensi wisata yang ada di pantai Tanjung Gelam berupa potensi wisata alam seperti daya tarik kawasan Pantai Tanjung Gelam dengan keindahan bawah laut serta flora dan fauna yang masih asri yang menjadikan Pantai Tanjung Gelam mempunyai daya tarik tersendiri. Potensi budaya seperti sedekah laut yang dilaksanakan di pantai Tanjung Gelam. Nilai indeks kesesuaian untuk rekreasi wisata pada ketiga stasiun memiliki kategori yang sama yaitu sangat sesuai (S1) dengan nilai pada stasiun masing masing 98\%, 95\%, dan 100\%. Berdasarkan hasil analisis daya dukung kawasan, kegiatan wisata berenang sangat sesuai dengan daya tampung sebanyak 135 orang/hari, wisata bananaboat berkategori sesuai dengan daya tampung 81 orang dan snorkling masuk kategori sesuai yaitu dengan daya tampung 17 orang.

\section{UCAPAN TERIMKASIH}

Penulis menyampaikan terima kasih kepada semua pihak yang telah memberikan bantuan dan fasilitas dalam penulisan jurnal ilmiah ini. 


\section{DAFTAR PUSTAKA}

Chasanah, I., P. W. Purnomo., dan Haeruddin. 2017. Analisis Kesesuaian Wisata Pantai Jodo Desa Sidorejo Kecamatan Gringsing Kabupaten Batang. Jurnal Pengelolaan Sumberdaya Alam dan Lingkungan. 7 (3): 235 - 243.

Effendi, H. 2003. Telaah Kualitas Air Bagi Pengelola Sumberdaya Lingkungan Perairan. Kanisius. Yogyakarta.

Febyanto. F., I. Praktikto., dan Koesoemadji. 2014. Analisis kesesuaian wisata pantai di Pantai Krakal Kabupaten Gunungkidul. Journal of Marine Research. 3 (4): 429-438

Hazen, G., D. Hartono., dan I. Cahayadinata. 2016. Studi Kesesuaian Pantai Laguna Desa Merpas Kecamatan Nasal Kabupaten Kaur Sebagai Daerah Pengembangan Pariwisata dan Konservasi. Jurnal Enggano. 1 (1): 33-41

Hendayawati, H. S., Budiono., dan Soemarno. 2010. Potensi Wisata Alam Pantai Bahari. [Prosiding]. Program Magister Pengelolaan Sumberdaya Lingkungan dan Pembangunan Program Pascasarjana, Universitas Brawijaya. Malang.

Hendyanto, R., C, A. Suryono dan I. Pratikto. 2014. Analisis Kesesuaian Wisata Pantai di Teluk Lombok Kabupaten Kutai Timur Kalimantan Timur. Jurnal Of Marine Research. 3(3): 211 - 215.

Indarjo, A., 2012. Strategi Pengembangan Ekowisata Bahari Berbasis Daya Dukung Lingkungan Di Pulau Panjang, Pantai Bandengan, Pantai Kartini, dan Teluk Awur Kabupaten Jepara. Disertasi. Sekolah Pascasarjana, Universitas Diponegoro, Semarang.

Juliana, L. Sya'rani., dan M. Zaenuri. 2013. Kesesuaian Daya Dukung Wisata Bahari di Perairan Bandengan Kabupaten Jeparan Jawa Tengah. Jurnal Perikanan dan Kelautan Tropis. IX (I): 1-7.

Kamah, M.H., F.M. Sahami., dan S.N Hamzah. 2013. Kesesuaian Wisata Pantai Berpasir Pulau Saronde Kecamatan Ponelo Kepulauan, Kabupaten Gorontalo Utara. [Artikel]. Sekolah Pascasarjana, Program Studi Manajemen Sumberdya Perairan, Gorontalo.3-9.

Kumaat, J.CH., M.T. Lasut., dan A. Wantasen. 2017. Aplikasi Sistem Informasi Geografis dalam Penentuan Kawasan Wisata Pantai di Kota Bitung. Jurnal Ilmiah Platax. 5 (1): 10-20.

Masrukhin, M. A.A., D, N. Sugianto., dan S. Satriadi. 2014. Studi Batrimetri dan Morfologi Dsara Laut dalam Penentuan Jalur Peletakan Pipa Bawah Laut. Jurnal Oseanografi. 3 (1) : 94-104.

Nugraha, H. P., Agus. I., M. Helmi. 2013. Studi Kesesuaian dan Daya Dukung Kawasan untuk Rekreasi Pantai di Pantai Panjang Kota Bengkulu. Journal Of Marine Research. 2 (2) : 130-139.

Panjaitan, R. A., Iskandar., dan H. S. Alisyahbana. 2012. Hubungan Perubahan Garis Pantai Terhadap Habitat Bertelur Penyu Hijau ( Chelonia mydas) di Pantai Pangumbahan Ujung Genteng, Kabupaten Sukabumi. Jurnal Perikanan dan Kelautan. 3 (3): $311-320$.

Sitompul, P, C, C., I. S., dan I. Pratikto. 2013. Studi Potensi Pulau Pisang Bagian Utara untuk Perencanaan Kawasan Wisata Pantai Kabupaten Lampung Barat, Provinsi Lampung. 2 (3): 138-146

Sudarto. W, Patty., dan A.A.Tarumingkang. 2013. Kondisi Arus Permukaan di Perairan Pantai : Pengamatan dengan Metode Legrangian. Jurnal Ilmu dan Perikanan Tangkap. 1 (3): 98-102

Sugiyono. 2012. Metode Penelitian Kuantitatif Kualitatif dan R \& D. Alfabeta. Bandung.

Tambunan, J. M., S. Anggoro dan H. Purnaweni. 2013. Kajian Kualitas Lingkungan dan Kesesuaian Wisata Pantai Tanjung Pesona Kabupaten Bangka. Prosiding Seminar Nasional Pengelolaan Sumberdaya Alam dan Lingkungan. Bulan Juni. di Kabupaten Bangka.

Yulianda, F. 2007. Ekowisata Sebagai Alternatif Pemanfaatan Sumberdaya Pesisir Berbasisi Konservasi. Fakultas Perikanan dan Ilmu Kelautan Institut Pertanian Bogor. Bogor.

Yulianda, F. A. Fahrudin. S. Hutabarat., H. Kusharjani. dan S.H. Kang. 2010. Pengelolaan Pesisir dan Laut Secara Terpadu. Pusdiklat Kehutanan Departemen Kehutanan RI. Jawa Barat.

Yulisa, E. N., J. Yar., dan D. Hartono. 2016. Analisis Kesesuaian dan Daya Dukung Ekowisata Pantai Kategori Rekreasi Pantai Laguna Desa Merpas Kabupaten Kaur. Jurnal Enggano. 1(1): 97-111 